\title{
Diagnostic Errors in Primary Care: Lessons Learned
}

\author{
John W. Ely, MD, Lauris C. Kaldjian, MD, PhD, and Donna M. D'Alessandro, MD
}

Background: Diagnostic errors occur more commonly than other kinds of errors, they are more likely to harm patients, and they are more likely to be preventable. Little is known about the presenting complaints, initial (incorrect) diagnoses, and physicians' personal lessons learned related to diagnostic errors.

Methods: In 2009 and 2010, we invited a random sample of 200 family physicians, 200 general internists, and 200 general pediatricians practicing in Iowa to describe an important diagnostic error using a 1-page, mailed questionnaire. The data were analyzed using quantitative and qualitative methods.

Results: The response rate was $34 \%$ (202 of 600 physicians). Common presenting complaints included abdominal pain $(n=27$ of 202 patients, 13\%); fever $(n=19 ; 9 \%)$; and fatigue $(n=15,7 \%)$. Common initial (incorrect) diagnoses included benign viral infections $(\mathrm{n}=35,17 \%)$; musculoskeletal pain $(n=21,10 \%)$; and chronic obstructive pulmonary disease/asthma $(n=13,6 \%)$. The 202 responding physicians described 254 personal lessons learned, which we used to develop a taxonomy of 24 generic lessons. Three common lessons were: (1) consider diagnosis $X$ in patients presenting with symptom Y ( $\mathrm{n}=37$ lessons, 15\%; eg, "Any discomfort above the umbilicus may be coronary artery disease."); (2) look beyond the initial, most obvious diagnosis $(n=26$ lessons, $10 \%)$; and (3) be alert to atypical presentations of disease $(n=24$ lessons, $9 \%)$.

Conclusions: In this study, diagnostic errors often were preceded by common symptoms and common, relatively benign initial diagnoses. The lessons learned often involved various aspects of broadening the differential diagnosis. (J Am Board Fam Med 2012;25:87-97.)

Keywords: Decision Making, Diagnostic Errors, Primary Health Care, Quality of Health Care

Diagnostic errors are relatively common compared with other types such as medication and surgical errors. ${ }^{1-8}$ The incidence of diagnostic errors is unknown but has been estimated at $5 \%$ to $15 \%$, depending on the setting and research methods. ${ }^{3,4,9,10}$ Diagnostic errors are the leading cause of malpractice claims and the leading cause of preventable

This article was externally peer reviewed.

Submitted 13 May 2011; revised 20 August 2011; accepted 25 August 2011.

From the Department of Family Medicine (JWE), the Department of Internal Medicine (LCK), and the Department of Pediatrics (DMD), University of Iowa Carver College of Medicine, Iowa City.

Funding: Support for this study was provided by the University of Iowa Departments of Family Medicine, Internal Medicine, and Pediatrics.

Conflict of interest: John Ely is being paid as a consultant by www.wemove.org, which is developing educational simulations to help students and physicians diagnose movement disorders. We do not believe this represents a conflict of interest but want to err on the side of full disclosure.

Corresponding author: John W. Ely, MD, Department of Family Medicine, 01291-D FPF, University of Iowa Carver College of Medicine, 200 Hawkins Drive, Iowa City, IA 52242-1097 (E-mail: john-ely@uiowa.edu). adverse events in hospitals. ${ }^{6,11}$ Physicians, nurses, and administrators are working to prevent medical errors by identifying faulty processes, changing systems, and building teams. ${ }^{12,13}$ But diagnosis is lonely work, often involving a single physician, and may be less amenable than other kinds of errors to system changes and teamwork.

\section{Introduction}

\section{The Problem}

Diagnostic errors often result from physicians' biases and failed heuristics (mental shortcuts). ${ }^{14-16} \mathrm{In}$ practice, the most common cognitive error is premature closure of the diagnostic process, in which the physician may not even consider the correct diagnosis as a possibility. ${ }^{17-20}$ For example, in a study of 583 diagnostic errors, Schiff and colleagues ${ }^{18}$ found that "failure or delay in considering the diagnosis" was the most common failure in the diagnostic process. The most commonly missed diagnoses-cancer, pulmonary embolus, coronary disease, aneurysms, appendicitis- have been docu- 
mented in previous studies, ${ }^{8,18,21,22}$ but little is known about the presenting complaints or initial (incorrect) diagnoses that precede these missed diagnoses. Knowledge of these precursors could help alert physicians to patients who warrant extra caution. Also, little is known about which cognitive biases are amenable to prevention, which preventive strategies would be effective, and how to incorporate these strategies into a busy physician's workflow. Physicians often report personal lessons learned ("take-home messages") after their errors, ${ }^{23,24}$ and these lessons could help guide efforts to develop preventive strategies.

\section{Study Purpose}

To help fill these knowledge gaps, we characterized important diagnostic errors made by practicing primary care physicians. We aimed to identify the presenting symptoms, initial (incorrect) diagnoses, final (correct) diagnoses, and personal lessons learned that are often associated with diagnostic errors.

\section{What This Study Adds}

This study supports the major findings of previous investigations of diagnostic errors. ${ }^{17,18}$ It adds new knowledge about the presenting symptoms, initial diagnoses, and personal lessons learned after important diagnostic errors.

\section{Methods \\ Subjects}

We invited a random sample of 600 Iowa primary care physicians to respond to a mailed questionnaire. The sample was stratified by specialty: 200 family physicians, 200 general pediatricians, and 200 general internists. All physicians in these specialties with active Iowa medical licenses, except house officers, were eligible. We obtained a database of physicians from the Iowa Board of Medical Examiners and transferred it to a statistical software program (Stata, Stata Corporation, College Station, TX). The database, which included the physician's specialty, address, and birth year, was obtained on June 18, 2009, and included 1282 family physicians, 474 general internists, and 266 general pediatricians. Each physician was assigned a random, computer-generated number and was grouped by specialty. After sorting by random number, the first
200 physicians from each specialty were invited to participate.

\section{Procedures}

We mailed an introductory letter and 1-page questionnaire (Appendix 1) to each physician. The questionnaire asked physicians to describe one important, missed, or delayed diagnosis, either their own or another physician's, using 6 open-ended prompts. The adjective "important" (left undefined) was included to help avoid trivial errors. The letter described our goal of developing diagnostic checklists, similar to pilots' preflight checklists, to help physicians avoid the most common cause of diagnostic error: failure to consider the correct diagnosis as a possibility. ${ }^{17,18,25}$ The questionnaire stated our interest in "diagnoses that were missed because they 'did not cross your mind' or were not 'on the radar screen' when you first saw the patient." Using free-text responses, each physician described the presenting complaint, the initial (incorrect) diagnosis, the final (correct) diagnosis, the patient's outcome, and any personal lessons learned. We also asked physicians to confirm whether they had considered the final (correct) diagnosis during the initial encounter. Each prompt was followed by an example response, based on an actual case of Lyme disease that was missed by one of the authors.

The questionnaires were anonymous; they lacked personal identifiers and identification numbers. To document participation, respondents were asked to return a $3 \times 5$ card with their identification number using a separate envelope. We mailed 2 reminder letters with questionnaires to nonresponders at 2 months and 4 months after the initial mailing. All questionnaires were returned between September 5, 2009, and December 18, 2010.

\section{Analysis}

We used descriptive statistics to determine the relative frequencies of presenting complaints, initial (incorrect) diagnoses, final (correct) diagnoses, and patient outcomes. We used a qualitative technique, known as the "constant comparison method," 26 to develop a taxonomy of personal lessons learned. With this method, each investigator worked independently to read 10 to 20 randomly selected lessons learned, develop a classification scheme, read several more, revise the scheme, and so on until all lessons were read and encompassed by a final tax- 
onomy. The goal was to discover common themes in the data and to define each one. As each investigator read the lessons, the existing themes were assigned to new lessons, new themes were added when necessary, and existing themes were revised to better encompass new lessons. Each investigator constantly compared new lessons to existing themes to determine whether they adequately described the lessons or whether new themes were needed. The themes were organized into a hierarchical outline that included main categories and subcategories. The subcategories were expressed as "generic lessons" in the taxonomy. One of the investigators (JE) synthesized the 3 independent efforts into a draft taxonomy, which was reviewed by the other 2 investigators (LK, DD) and revised before a final version was approved by all. The study was approved by the University of Iowa Institutional Review Board.

\section{Results}

\section{Response Rate}

We received 202 usable questionnaires, resulting in a 34\% response rate. After excluding 11 physicians who returned blank questionnaires with notes stating they no longer practiced medicine and 32 physicians whose questionnaires could not be delivered or forwarded by the post office, the adjusted response rate was $36 \%$ (202 of 557). The mean age of respondents was greater than the mean age of the invited sample (51.8 vs 49.0 years; $P<.01$ ). The proportion of female respondents was similar to the proportion of women in the invited sample (38.5\% vs $40.3 \% ; P=.62)$.

Table 1. Common Presenting Complaints in Patients Who Experienced a Diagnostic Error

\begin{tabular}{lc}
\hline Presenting Complaint & Patients \\
\hline Abdominal pain & $27(13)$ \\
Fever & $19(9)$ \\
Fatigue & $15(7)$ \\
Dyspnea & $13(6)$ \\
Rash & $11(5)$ \\
Cough & $10(5)$ \\
Chest pain & $9(4)$ \\
Leg pain & $9(4)$ \\
Back pain & $8(4)$ \\
Nausea and vomiting & $8(4)$ \\
Other presenting complaints* & $73(36)$ \\
Total & $202(100)$ \\
\hline
\end{tabular}

Values provided as $\mathrm{n}(\%)$.

*Encompasses 38 other complaints.
Table 2. Common Initial (Incorrect) Diagnoses in Patients Who Experienced a Diagnostic Error

\begin{tabular}{lc}
\hline Initial (Incorrect) Diagnosis & Patients \\
\hline Benign viral infection & $35(17)$ \\
Musculoskeletal pain & $21(10)$ \\
COPD/asthma & $13(6)$ \\
Benign skin lesion & $9(4)$ \\
Pneumonia & $8(4)$ \\
Urinary tract infection & $7(3)$ \\
Coronary artery disease & $4(2)$ \\
Constipation & $4(2)$ \\
Depression & $4(2)$ \\
Viral gastroenteritis & $4(2)$ \\
Other* & $93(46)$ \\
Total & $202(100)$ \\
\hline
\end{tabular}

Values provided as $\mathrm{n}(\%)$.

*Encompasses 60 other initial diagnoses.

COPD, chronic obstructive pulmonary disease.

\section{Presenting Complaints, Initial Diagnoses, and Final Diagnoses}

Common presenting complaints, initial diagnoses, and final diagnoses are listed in Tables 1, 2, and 3 . The 3 complaints most often associated with diagnostic errors in this study were abdominal pain, fever, and fatigue. Common initial (incorrect) diagnoses included benign viral infections (24 respiratory or nonspecific and 11 gastroenteritis), musculoskeletal pain, and chronic obstructive pulmonary

Table 3. Common Final (Correct) Diagnoses in Patients Who Experienced a Diagnostic Error

\begin{tabular}{|c|c|}
\hline Final (Correct) Diagnosis & Patients \\
\hline Cancer* & $33(16)$ \\
\hline Pulmonary embolus & $13(6)$ \\
\hline Coronary artery disease & $10(5)$ \\
\hline Aneurysm $^{\dagger}$ & $8(4)$ \\
\hline Appendicitis & $6(3)$ \\
\hline Kawasaki disease & $5(2)$ \\
\hline Meningitis & $5(2)$ \\
\hline Pneumonia & $5(2)$ \\
\hline Temporal arteritis/polymyalgia rheumatica & $5(2)$ \\
\hline Child abuse & $3(1)$ \\
\hline Other $^{\ddagger}$ & $109(54)$ \\
\hline Total & $202(100)$ \\
\hline
\end{tabular}


disease/asthma. Common final (correct) diagnoses included cancer, pulmonary embolus, and coronary artery disease. In response to one of the questionnaire items, 166 of the 202 physicians $(82 \%)$ confirmed that they had not considered the final diagnosis as a possibility.

\section{Analysis of Sequences}

We searched unsuccessfully for common sequences involving the complaint, followed by the initial diagnosis, followed by the final diagnosis. For example, in the 27 patients who presented with abdominal pain, the most common initial diagnosis was gall bladder disease $(n=4)$. The remaining 23 patients had 18 other initial diagnoses. The 4 patients who initially were diagnosed with gallbladder disease had 4 unique final diagnoses: pancreatitis, ovarian cancer, pulmonary embolus, and herpes zoster. In the 19 patients who presented with fever, 14 were initially diagnosed with benign viral illness and, of these 14, the final diagnosis was pneumonia in 3 and Kawasaki disease in 2. The remaining 9 patients had 9 unique final diagnoses. Similarly, we found no commonly recurring sequences following the other presenting complaints.

Conversely, we started with the final diagnoses and searched backward for the preceding presenting complaints and initial diagnoses. For the 33 patients with cancer, the most common initial diagnosis was musculoskeletal pain $(\mathrm{n}=7)$. The remaining 26 patients had 20 other initial diagnoses. For the 7 patients who were diagnosed initially with musculoskeletal pain, the presenting complaints were back pain $(n=2)$, fatigue $(n=2)$, chest pain $(\mathrm{n}=1)$, leg pain $(\mathrm{n}=1)$, and shoulder pain $(\mathrm{n}=1)$. Similarly, we found no commonly repeated sequences for pulmonary embolus. For the 13 patients with missed pulmonary emboli, 5 had an initial diagnosis of chronic obstructive pulmonary disease/asthma; 3 of these 5 presented with cough and 2 presented with dyspnea.

We classified the initial and final diagnoses as serious versus benign and common versus uncommon. For example, pulmonary embolus was classified as serious and uncommon (relative to other causes of the presenting complaint in primary care). This classification would theoretically allow 16 possible scenarios. One scenario would be a common, benign initial diagnosis followed by an uncommon, serious final diagnosis. This was, in fact, the most common scenario in this study, occurring in 142 of the 202 patients (70\%). The second most common scenario, occurring in 26 patients $(13 \%)$, was an uncommon and serious initial diagnosis followed by an uncommon and serious (but different) final diagnosis.

\section{Patient Outcomes}

The final outcome was good for 110 of the 202 patients (54\%): 71 had no adverse outcome and 39 had temporary morbidity. The outcome was bad for 74 of the 202 patients (37\%): 50 died and 24 survived with permanent disabilities. The outcome was unknown for the remaining 18 patients (9\%).

\section{Lessons Learned}

The 202 physicians described up to 3 patient-specific lessons per error, for a total of 254 lessons, which we organized into a taxonomy containing 8 main categories and 24 generic lessons (Table 4 and Appendix 2). Most of the lessons in this study ( $\mathrm{n}=157 ; 62 \%)$ involved some aspect of broadening the differential diagnosis. This advice to broaden the differential diagnosis was cited just as commonly by the 36 physicians who considered the final diagnosis initially as it was by the 166 who had not considered it: 27 broaden-differential lessons of 42 total lessons (64\%) from physicians who considered the diagnosis versus 130 of 212 total lessons $(61 \%)$ from physicians who had not considered it $(P=.72)$. A common generic lesson was to consider specific diagnosis $\mathrm{X}$ in patients presenting with specific symptom Y. For example, after missing an acute myocardial infarction in a patient with ear pain, one family physician said, "Any pain without apparent source on the left side of head, neck, chest, or arm needs a cardiac workup." Similarly, an internist said, "Any discomfort above the umbilicus may be [coronary artery disease]."

Many lessons addressed well-known cognitive biases, such as anchoring, diagnostic momentum, and premature closure. ${ }^{27}$ As an example of anchoring, one physician, who missed thrombotic thrombocytopenia purpura in a patient complaining of arm and leg numbness, said, "Even depressed patients with extensive whole body complaints consistent with fibromyalgia may have an alternative diagnosis." Other lessons did not clearly address previously described biases. For example, one family physician described a patient who was correctly diagnosed with diabetic ketoacidosis, but the underlying cause of the acidosis (endocarditis) was 
Table 4. Common Generic Lessons Learned ("Take-Home Messages”) Described by Physicians Following a Diagnostic Error

\begin{tabular}{|c|c|c|c|}
\hline Generic Lesson & Description & Example & $\begin{array}{l}\text { Patient-Specific } \\
\text { Lessons }\end{array}$ \\
\hline $\begin{array}{l}\text { Consider specific disease in } \\
\text { specific circumstances }\end{array}$ & $\begin{array}{l}\text { Be alert to the possibility of disease(s) } \\
\text { X under circumstance(s) Y. } \\
\text { Anyone with symptom(s) X should } \\
\text { have disease(s) Y ruled out or at } \\
\text { least considered. }\end{array}$ & $\begin{array}{l}\text { Missed severe hyponatremia, sodium } \\
115 \mathrm{mEq} / \mathrm{L} \text {, in a woman } \\
\text { presenting with anxiety: "Include } \\
\text { electrolyte imbalance in the } \\
\text { differential diagnosis of anxiety." }\end{array}$ & $37(15)$ \\
\hline $\begin{array}{l}\text { Look beyond the initial } \\
\text { diagnosis }\end{array}$ & $\begin{array}{l}\text { Look beyond the obvious. } \\
\text { Although we always attempt to find } \\
\text { one diagnosis that explains all the } \\
\text { findings, we should never assume } \\
\text { that only one condition explains } \\
\text { everything. }\end{array}$ & $\begin{array}{l}\text { Missed pulmonary embolus in a } \\
\text { woman presenting with asthma } \\
\text { exacerbation: "Do not assume the } \\
\text { obvious." }\end{array}$ & $26(10)$ \\
\hline $\begin{array}{l}\text { Be alert to atypical } \\
\text { presentations }\end{array}$ & $\begin{array}{l}\text { Be alert to nonclassic or atypical } \\
\text { presentation of diseases that do not } \\
\text { follow the normal pattern. } \\
\text { Remember that disease X can } \\
\text { masquerade as disease Y. } \\
\text { Do not rule out serious disease solely } \\
\text { on the basis of age or a negative } \\
\text { test result or a negative element of } \\
\text { the history or physical exam. } \\
\text { Be aware of blunted symptoms in the } \\
\text { elderly. }\end{array}$ & $\begin{array}{l}\text { Missed myocardial infarction in a } \\
\text { man presenting with heartburn } \\
\text { after running out of omeprazole: } \\
\text { "Always consider atypical } \\
\text { presentations with anyone with } \\
\text { any kind of chest pain even } \\
\text { though patient is convinced } \\
\text { otherwise!" }\end{array}$ & $24(9)$ \\
\hline $\begin{array}{l}\text { Be more aggressive with } \\
\text { diagnostic testing }\end{array}$ & $\begin{array}{l}\text { Be more aggressive with diagnosis in } \\
\text { specific circumstances, but also } \\
\text { maintain selectivity when ordering } \\
\text { tests. }\end{array}$ & $\begin{array}{l}\text { Missed severe pulmonary hypertension } \\
\text { in woman presenting with dyspnea } \\
\text { and hypoxia: "Consider testing for } \\
\text { pulmonary hypertension earlier } \\
\text { [rather] than later." }\end{array}$ & $19(8)$ \\
\hline $\begin{array}{l}\text { Reconsider diagnosis if } \\
\text { patient follows } \\
\text { unexpected course }\end{array}$ & $\begin{array}{l}\text { Reassess and repeat the evaluation if } \\
\text { the patient does not respond as } \\
\text { expected or the course is not as } \\
\text { expected or not everything fits. }\end{array}$ & $\begin{array}{l}\text { Missed pancreatic cancer in an elderly } \\
\text { man with weakness: "When } \\
\text { something doesn't make sense, keep } \\
\text { searching! . . persistent weakness } \\
\text { despite treating UTI." }\end{array}$ & $18(7)$ \\
\hline $\begin{array}{l}\text { Consider uncommon } \\
\text { conditions }\end{array}$ & & $\begin{array}{l}\text { Missed neurosyphilis in an elderly } \\
\text { woman presenting with delirium } \\
\text { and confusion: "We were always } \\
\text { taught that syphilis was the 'great } \\
\text { imitator' and to check for it but it } \\
\text { had been a long time since I had } \\
\text { seen anything but a false positive. } \\
\text { Should still be considered in acute } \\
\text { neuropsychiatric presentations. Just } \\
\text { because it isn't common does not } \\
\text { mean a diagnosis should not be } \\
\text { considered!" }\end{array}$ & $15(6)$ \\
\hline Do complete physical exam & $\begin{array}{l}\text { Do a better physical exam in general } \\
\text { and in specific circumstances. }\end{array}$ & $\begin{array}{l}\text { Missed ovarian cancer in a woman } \\
\text { presenting with pelvic discomfort: } \\
\text { "I did a lousy pelvic exam. Be } \\
\text { methodical, do not guess." }\end{array}$ & $15(6)$ \\
\hline $\begin{array}{l}\text { Broaden the differential in } \\
\text { general }\end{array}$ & $\begin{array}{l}\text { General statement to broaden the } \\
\text { differential diagnosis. }\end{array}$ & $\begin{array}{l}\text { Missed ischemic bowel in a woman } \\
\text { with diarrhea and fever: "I learned } \\
\text { to be more diligent and } \\
\text { methodical in broadening my } \\
\text { differential." }\end{array}$ & $14(6)$ \\
\hline $\begin{array}{l}\text { Arrange more reliable, } \\
\text { specific follow-up }\end{array}$ & $\begin{array}{l}\text { Arrange better follow-up in specific } \\
\text { circumstances; provide return } \\
\text { parameters; take a more active role } \\
\text { in arranging follow-up; physician } \\
\text { should initiate follow-up, such as a } \\
\text { phone call, not just leave it up to } \\
\text { the patient. }\end{array}$ & $\begin{array}{l}\text { Missed endometrial cancer in a } \\
\text { woman with abnormal uterine } \\
\text { bleeding: "Call patients on the } \\
\text { phone and don't leave a follow up } \\
\text { plan to the next visit. They can } \\
\text { move!" }\end{array}$ & $11(4)$ \\
\hline
\end{tabular}




\begin{tabular}{|c|c|c|c|}
\hline Generic Lesson & Description & Example & $\begin{array}{c}\text { Patient-Specific } \\
\text { Lessons }\end{array}$ \\
\hline $\begin{array}{l}\text { Consider "don't-miss" } \\
\text { diagnoses }\end{array}$ & Rule out the worst-case scenario. & $\begin{array}{l}\text { Missed coronary disease in a man } \\
\text { presenting with respiratory } \\
\text { distress: "If there is a possibility } \\
\text { of a disease with a high morbidity, } \\
\text { I should at least do an initial } \\
\text { screening." }\end{array}$ & $8(3)$ \\
\hline Other* & & & $67(26)$ \\
\hline Total $^{\dagger}$ & & & $254(100)$ \\
\hline
\end{tabular}

Values provided as $\mathrm{n}(\%)$.

*Encompasses 14 other lessons.

${ }^{\dagger}$ The 202 physicians described up to 3 lessons per error, for a total of 254 lessons.

UTI, urinary tract infection.

missed. Still others seemed to support certain biases as being paradoxically helpful. For example, base-rate neglect is the tendency to ignore the true prevalence of a disease and distort Bayesian reasoning. ${ }^{27}$ But, after missing a case of neurosyphilis, one family physician said, “Just because it isn't common does not mean a diagnosis should not be considered!"

Physicians often tempered their lessons by including the opposite view. For example, (paraphrasing):

- "Listen to the patient, but don't let them convince you they don't have something serious."

- "Refer sooner, but don't stop thinking [about] or abandon the patient after you refer."

- "Try to explain all findings with one diagnosis, but sometimes more than one thing is going on."

- "Get more tests, but it's not really feasible to do that either."

\section{Discussion \\ Main Findings}

The most common pathway leading to error in this study was the assignment of common benign diagnoses to patients with uncommon serious diseases. Following their errors, many physicians said that, in the future, they would broaden their differential diagnosis and consider specific "don't-miss" diagnoses for specific presenting complaints.

\section{Previous Studies}

The most frequently missed diagnoses in this study were similar to those found in previous studies. ${ }^{8,18,21,22,28}$ Cancer, myocardial infarction, and pulmonary embolus were among the top 10 missed diagnoses in 4 recent studies of diagnostic error. $^{8,18,21,22}$ Other diagnoses, such as fractures and drug reactions, were more frequent in these studies than in ours, possibly because of different sampling methods (eg, malpractice claims ${ }^{8,21,22}$ rather than self-reports); settings (eg, emergency departments ${ }^{21}$ rather than primary care clinics); and specialties (eg, specialists ${ }^{18}$ rather than generalists).

Previous studies have not reported presenting complaints or initial diagnoses associated with diagnostic errors. ${ }^{8,18,21,22}$ Autopsy studies have compared the "anatomic diagnosis" with the final "clinical diagnosis" but not the initial diagnosis. ${ }^{4,29}$ Studies of malpractice claims found worse patient outcomes than our study and worse outcomes than a previous physician survey of diagnostic errors, ${ }^{18}$ probably because of the plaintiff's need to document a bad outcome.

Few studies have documented personal lessons learned following errors. In a study of house officers' errors, which was not limited to diagnostic errors, personal lessons included "seek more advice," "read," "pay more attention to detail," and "personally confirm data." 23 In a study of family physicians' errors, again not limited to diagnostic errors, personal lessons included "be more aggressive diagnostically," "resist outside distractions," and "broaden the differential diagnosis." 24

\section{Limitations}

Our findings should be interpreted in light of several limitations. The commonly cited lesson to broaden the differential diagnosis could have resulted from our stated preference for diagnoses that 
"did not cross your mind." However, the $20 \%$ of physicians who initially had considered the correct diagnosis were just as likely as those who had not to report this lesson. Although failure to consider the correct diagnosis is the most common cause of diagnostic errors, simply broadening the differential diagnosis without critical thought easily could lead to excessive testing. ${ }^{30}$

The inclusion of the missed Lyme disease case could have influenced respondents' answers and their selection of errors, but we judged this risk to be outweighed by the benefits of self-disclosure, which often improves participant disclosure of sensitive information. ${ }^{31,32}$

The selection of errors may have been influenced by the physicians' level of comfort in reporting them, with high rates of "forgivable" errors, rare diseases, and good outcomes. However, most of the errors were not trivial and the most commonly missed diagnoses were similar to those in previous studies. ${ }^{8,18,21,22,28}$ Physicians may not have been aware of their errors if the patient recovered uneventfully or the correct diagnosis was later made without the physician's knowledge. We did not confirm the existence or nature of errors by reviewing medical records or interviewing patients. However, other methods for identifying diagnostic errors, such as autopsies, ${ }^{4}$ hospital admissions, ${ }^{33}$ and malpractice claims, ${ }^{22}$ are subject to their own biases. Even large, population-based studies using medical records have not included errors among ambulatory patients or primary care providers or errors that did not result in adverse events. ${ }^{6,34}$

Because of this error selection method, we were unable to identify the most common presenting complaints, initial (wrong) diagnoses, or final (correct) diagnoses associated with diagnostic errors. Such knowledge would require a prospective cohort study that starts with presenting complaints rather than a retrospective case series that starts with diagnostic errors. We were not able to find previous prospective cohort studies of diagnostic errors. Previous retrospective cohort studies of medical errors have been limited to hospitalized patients with adverse outcomes; they have been inefficient in identifying errors because they required a review of hundreds of medical records before finding an adverse outcome associated with a diagnostic error, and they were unable to link diagnostic errors with presenting complaints, initial (wrong) diagnoses, or personal lessons learned. ${ }^{6,34}$
We identified symptoms that commonly precede missed cases of disease, but these symptoms are not necessarily the most common among cases in general. For example, the most common symptoms of pulmonary embolus in this study were cough and chest pain, whereas the most common symptom in a large population-based study was dyspnea. ${ }^{35}$

The response rate was low but similar to other studies involving physician surveys of sensitive topics. ${ }^{18}$ The small sample may have contributed to our failure to find common sequences of complaints, initial diagnoses, and final diagnoses. We might have increased the response rate by using close-ended prompts that required only a check mark, rather than opened-ended questions that required prose, but we doubted our ability to anticipate the full range of possible responses and incorporate these into a multiple-choice format.

Although the wording of the questionnaire encouraged self-report, we did not ask explicitly whether the error was committed by the responding physician or a different physician. In the 13 cases in which it was clear that the error was committed by another physician, the responding physician was able to report the details of the case, including the presenting complaint and the initial (wrong) diagnosis.

\section{Implications and Conclusions}

Physicians may find it helpful to know which presenting complaints are commonly associated with diagnostic errors because these complaints might deserve extra caution. Physicians already have great respect for chest pain, and moderate respect for abdominal pain, but possibly less respect for fatigue. However, our study looked at errors retrospectively. A prospective study of fatigue might have reached different conclusions about the prevalence of its serious causes.

Cognitive errors have been thoroughly described, but we know little about how to prevent them. De-biasing strategies, such as taking a diagnostic time out to review a checklist, have been suggested but require further development. ${ }^{25,36,37}$ As physicians, we value our ability to generate a complete differential diagnosis from memory, but as Donald Berwick said, "Genius diagnosticians make great stories, but they don't make great health care." ${ }^{38}$ Airline pilots do not rely on their memories to assure safety. They rely on checklists. 
Cognitive aids based on studies like this one might include checklists ${ }^{25}$ and computerized decision support tools ${ }^{39}$ that help physicians avoid the most common cause of diagnostic error: failure to consider the correct diagnosis. The take-home message is not to do more tests to rule out every possible diagnosis. The take-home message is to get every reasonable diagnosis on the "radar screen." Most of those diagnoses immediately will come back off the radar screen based on the physician's further consideration of the patient's presentation, additional history taking, and additional physical examination procedures, but not, in most cases, further testing.

The authors are indebted to Amy Miranda, who coordinated the mailed survey.

\section{References}

1. Chandra A, Nundy S, Seabury SA. The growth of physician medical malpractice payments: evidence from the National Practitioner Data Bank. Health Aff (Millwood). 2005;Suppl Web Exclusives:W5240-W5-249.

2. Greenwald L. Failure to diagnose: putting the pieces together. A Review of closed claims in selected specialties 2002-2004. Boston, MA: ProMutual Group; 2004.

3. Berner ES, Graber ML. Overconfidence as a cause of diagnostic error in medicine. Am J Med 2008; 121(5A):S2-S23.

4. Shojania KG, Burton EC, McDonald KM, Goldman L. Changes in rates of autopsy-detected diagnostic errors over time: a systematic review. JAMA 2003; 289(21):2849-56.

5. Katz HP, Kaltsounis D, Halloran L, Mondor M. Patient safety and telephone medicine: some lessons from closed claim case review. J Gen Intern Med 2008;23(5):517-22.

6. Leape LL, Brennan TA, Laird N, et al. The nature of adverse events in hospitalized patients: results of the Harvard Medical Practice Study II. N Engl J Med 1991;324:377-84.

7. Singh H, Thomas EJ, Petersen LA, Studdert DM. Medical errors involving trainees: a study of closed malpractice claims from 5 insurers. Arch Intern Med 2007;167(19):2030-6.

8. Phillips RL Jr, Bartholomew LA, Dovey SM, Fryer GE Jr, Miyoshi TJ, Green LA. Learning from malpractice claims about negligent, adverse events in primary care in the United States. Qual Saf Health Care 2004;13(2):121-6.

9. Elstein AS. Clinical reasoning in medicine. In: Higgs J, Jones MA, eds. Clinical Reasoning in the Health Professions. Woburn, MA: Butterworth-Heinemann; 1995:49-59.
10. O'Connor PM, Dowey KE, Bell PM, Irwin ST, Dearden $\mathrm{CH}$. Unnecessary delays in accident and emergency departments: do medical and surgical senior house officers need to vet admissions? J Accid Emerg Med 1995;12(4):251-4.

11. Graber M. Diagnostic errors in medicine: a case of neglect. Jt Comm J Qual Patient Saf 2005;31(2): $106-13$.

12. Haynes AB, Weiser TG, Berry WR, et al. A surgical safety checklist to reduce morbidity and mortality in a global population. N Engl J Med 2009;360(5): 491-9.

13. Pronovost P, Needham D, Berenholtz S, et al. An intervention to decrease catheter-related bloodstream infections in the ICU. N Engl J Med 2006; 355(26):2725-32.

14. Croskerry P, Cosby KS, Schenkel SM, Wears RL. Patient Safety in Emergency Medicine. Philadelphia: Lippincott Williams \& Wilkins; 2009.

15. Tversky A, Kahneman D. Judgement under uncertainty: heuristics and biases. Science 1974;185:1124-31.

16. Elstein AS, Schwarz A. Clinical problem solving and diagnostic decision making: selective review of the cognitive literature. BMJ 2002;324(7339):729-32.

17. Graber ML, Franklin N, Gordon R. Diagnostic error in internal medicine. Arch Intern Med 2005; 165(13):1493-9.

18. Schiff GD, Hasan O, Kim S, et al. Diagnostic error in medicine: analysis of 583 physician-reported errors. Arch Intern Med 2009;169(20):1881-7.

19. Kostopoulou O, Devereaux-Walsh C, Delaney BC. Missing celiac disease in family medicine: the importance of hypothesis generation. Med Decis Making 2009;29(3):282-90.

20. Kostopoulou O, Oudhoff J, Nath R, et al. Predictors of diagnostic accuracy and safe management in difficult diagnostic problems in family medicine. Med Decis Making 2008;28(5):668-80.

21. Kachalia A, Gandhi TK, Puopolo AL, et al. Missed and delayed diagnoses in the emergency department: a study of closed malpractice claims from 4 liability insurers. Ann Emerg Med 2007;49(2): 196-205.

22. Gandhi TK, Kachalia A, Thomas EJ, et al. Missed and delayed diagnoses in the ambulatory setting: a study of closed malpractice claims. Ann Intern Med 2006;145(7):488-96.

23. Wu AW, Folkman S, McPhee SJ, Lo B. Do house officers learn from their mistakes? JAMA 1991;265: 2089-94.

24. Ely JW, Levinson W, Elder NC, Mainous AG III, Vinson DC. Perceived causes of family physicians' errors. J Fam Pract 1995;40:337-44.

25. Ely JW, Graber ML, Croskerry P. Checklists to reduce diagnostic errors. Acad Med 2011;86(3):307-13.

26. Strauss A, Corbin JM. Basics of Qualitative Research: Techniques and Procedures for Developing Grounded Theory. Thousand Oaks, CA: Sage; 1998. 
27. Croskerry P. Cognitive and affective dispositions to respond. In: Croskerry P, Cosby K, Schenkel S, Wears R (eds). Patient Safety in Emergency Medicine. Philadelphia: Lippincott Williams \& Wilkins; 2009:219-27.

28. Bernicker EH, Atmar RL, Schaffner DL, Greenberg SB. Unanticipated diagnoses found at autopsy in an urban public teaching hospital. Am J Med Sci 1996; 311(5):215-20.

29. Cardoso MP, Bourguignon DC, Gomes MM, Saldiva PH, Pereira CR, Troster EJ. Comparison between clinical diagnoses and autopsy findings in a pediatric intensive care unit in Sao Paulo, Brazil. Pediatr Crit Care Med 2006;7(5):423-7.

30. Graber M, Gordon R, Franklin N. Reducing diagnostic errors in medicine: what's the goal? Acad Med 2002;77(10):981-92.

31. Davis JD, Skinner AEG. Reciprocity of self-disclosure in interviews: modeling or social exchange? J Pers Soc Psychol 1974;29:779-84.

32. Jourard SM. The Transparent Self. Princeton, NJ: Van Nostrand Rheinhold; 1971.

33. Singh H, Thomas EJ, Khan MM, Petersen LA. Identifying diagnostic errors in primary care using an electronic screening algorithm. Arch Intern Med 2007;167(3):302-8.

34. Thomas EJ, Studdert DM, Burstin HR, et al. Incidence and types of adverse events and negligent care in Utah and Colorado. Med Care 2000;38(3):261-71.

35. Stein PD, Beemath A, Matta F, et al. Clinical characteristics of patients with acute pulmonary embolism: data from PIOPED II. Am J Med 2007; 120(10):871-9.

36. Croskerry P. Cognitive forcing strategies in clinical decision making. Ann Emerg Med 2003;41(1):110-20.

37. Croskerry P. The importance of cognitive errors in diagnosis and strategies to minimize them. Acad Med 2003;78(8):775-80.

38. Gaither C. What your doctor doesn't know could kill you. The Boston Globe. July 14, 2002.

39. Garg AX, Adhikari NK, McDonald H, et al. Effects of computerized clinical decision support systems on practitioner performance and patient outcomes: a systematic review. JAMA 2005;293(10):1223-38.

\section{Appendix 1: Physician Questionnaire}

Please briefly describe one important missed or delayed diagnosis, either your own or another physician's, using the 6 questions below. We are particularly interested in diagnoses that were missed because they "did not cross your mind" or were not "on the radar screen" when you first saw the patient.

1. What was the presenting complaint or problem? True example from Fobn Ely: "Approximately 50-year-old woman seen in clinic com- plaining of a fever and rash with large blotches on her chest and abdomen."

2. What was your initial diagnosis? Example: "viral exanthem."

3. What was the final diagnosis? Example: "Lyme disease. Her fever was persistent so I referred her to Infectious Disease where she was seen 2 weeks later and they made the diagnosis immediately."

4. Did you consider the final diagnosis as a possibility when you saw the patient initially? Was it on your radar screen? Example: "No it was not on my radar screen at all."

5. What was the patient's outcome? Example: "She has done well so far, but the delay in diagnosis and treatment was not good."

6. Did you have any take-home messages for yourself? Example: "Yes, fever and rash in an adult requires urgent evaluation and should not be blamed on a viral exanthem, the way we do with kids.”

\section{Appendix 2: Taxonomy of Generic Lessons Learned Described by Physicians Following a Diagnostic Error (Based on $n=254$ Patient- Specific Lessons)}

1. Broaden the Differential Diagnosis ( $n=157,62 \%$ )

1.1. Broaden the Differential in General $(n=14 ; 6 \%)$

General statement to broaden the differential diagnosis. Example: Missed ischemic bowel: "I learned to be more diligent and methodical in broadening my differential."

\subsection{Look Beyond the Initial Diagnosis $(n=26 ; 10 \%)$}

Look beyond the obvious. Although we always attempt to find one diagnosis that explains all the findings, we should never assume that only one condition explains everything. Example: Missed shaken-baby syndrome: "I now always assume that there are other causes out there for vomiting repeatedly, and I ask a lot more questions.”

\subsection{Reconsider Diagnosis If Patient Follows Unexpected Course $(n=18 ; 7 \%)$}

Reassess and repeat the evaluation if the patient does not respond as expected or the course is not as expected or not everything fits. Example: Missed pancreatic cancer: "When something doesn't make sense, keep searching! Persistent weakness despite treating [urinary tract infection].” 


\subsection{Consider Uncommon Conditions ( $n=15$; $6 \%$ )}

Example: Missed neurosyphilis: "We were always taught that syphilis was the "great imitator" and to check for it but it had been a long time since I had seen anything but a false positive. Should still be considered in acute neuropsychiatric presentations. Just because it isn't common does not mean a diagnosis should not be considered!"

\subsection{Consider Specific Disease in Specific Circumstances $(n=37 ; 15 \%)$}

Be alert to the possibility of disease(s) $\mathrm{X}$ under circumstance(s) Y. Anyone with symptom(s) X should have disease(s) Y ruled out or at least considered. Example: Missed slipped capital femoral epiphysis in a girl with knee pain: "Should remember what peds ortho says: 'The knee weeps for the hip."”

\subsection{Be Alert To Atypical Presentations $(n=24 ; 9 \%)$}

Be alert to nonclassic or atypical presentation of diseases that do not follow the normal pattern. Remember that disease $\mathrm{X}$ can masquerade as disease Y. Do not rule out serious disease solely based on age or a negative test result or a negative element of the history or physical examination. Be aware of blunted symptoms in the elderly. Example: Missed celiac disease: " $10 \%$ of kids with celiac disease have chronic constipation instead of diarrhea."

\subsection{Consider "Don't-Miss" Diagnoses $(n=8 ; 3 \%)$}

Rule out the worst case scenario. Example: Missed coronary disease: "If there is a possibility of a disease with a high morbidity, I should at least do an initial screening."

\subsection{Search for Underlying Causes ( $n=4,2 \%$ )}

Look for the underlying cause of the problem; do not stop after naming the problem. Example: Missed dissecting thoracic aortic aneurysm: "Always determine the cause of an ileus."

\subsection{Incorporate Specific Factors Into the Diagnostic} Process $(n=11 ; 4 \%)$

1.9.1. Take Patient Complaints and Requests More Seriously $(n=5 ; 2 \%)$. Conversely, do not let the patient dissuade you from ruling out a serious disease. Example: Missed renal-cell carcinoma: "Reconsider seriousness of patient's request. Patient told me she wanted a 'full body scan' because she just didn't feel right. Saw GI, saw oncology.”

1.9.2. Incorporate Specific Risk Factors ( $n=4 ; 2 \%$ ). Incorporate risk factors when formulating differential diagnosis. Look at the whole picture including history and risk factors. Example: Missed pulmonary embolus: "She was postop from orthopedic surgery and that didn't trip my trigger for increased risk of PE. She also had bilateral edema and negative Homan sign. She said the edema was chronic but I should have checked old notes."

1.9.3. Consider Your Intuition ( $n=2 ; 1 \%$ ). Listen to your gut. Let your intuition override other opinions when they do not seem correct. Example: Missed spinal tumor in child: "Took several months to get the diagnosis and several specialists told me there was 'nothing wrong'-My take home message was to be persistent and listen to the little voice in my head when it says something is wrong!"

2. Be More Aggressive With Patient Management $(n=36$; $14 \%)$

\subsection{Be More Aggressive With Diagnostic Testing ( $n=$ 19; $8 \%)$}

Be more aggressive with diagnosis in specific circumstances, but also maintain selectivity when ordering tests. Example: Missed meningococcal meningitis: "The only thing I could conclude was, should I draw a [complete blood count] and blood culture on every febrile infant? And concluded that I couldn't really have done that either. The scenario still haunts me."

\subsection{Be More Aggressive With Treatment $(n=4 ; 2 \%)$}

Treat sooner, sometimes before the diagnosis is confirmed, if the potential disease needs early treatment to avoid morbidity or mortality. Example: Missed cutaneous herpes simplex infection: "Use antivirals early."

\subsection{Seek Consultation Sooner $(n=7 ; 3 \%)$}

When things are not clear, seek another opinion from a specialist or more experienced colleague. Seek another opinion in specific circumstances. $E x-$ ample: Missed episcleritis: "Any red eye with globe pain should be referred to ophtho immediately."

\subsection{Do Not Blindly Accept Consultant's Opinion ( $n=6 ; 2 \%)$}

Be more aggressive after referral. Referral may not be enough. Your job is not always done after referral. Do 
not assume the specialist knows more than you do. Look at the radiographs, not just the report. Example: Missed Wegener granulomatosis: "Just because you consult 1 or 2 subspecialists does not mean you can quit trying to figure out why a patient continues to deteriorate-keep trying. We are physicians—not technicians-be the patient's advocate."

\section{Take a Complete History $(n=11 ; 4 \%)$}

3.1. Take a Complete History from the Patient $(n=8 ; 3 \%)$ Example: Missed neuroblastoma: "A few clues were missed including significant anemia, lethargy and significant loss of weight, decreased appetite etc. A careful history is the hallmark of correct diagnosis, even today."

\subsection{Review the Medical Record Thoroughly ( $n=3 ; 1 \%)$}

Example: Missed myxedema after failure to restart thyroid replacement after surgery: "Be more careful to check all meds reordered after surgery.")

\section{Do Complete Physical Examination ( $n=15 ; 6 \%)$}

Do a better physical examination in general and in specific circumstances. Example: Missed retinoblastoma: "Double check red reflex examination of eye. Ask for pictures-absent red reflex in one eye."

\section{Be More Careful ( $n=5 ; 2 \%)$}

Be more careful in general and in specific circumstances. Example: Infant with low back skin tag, missed tethered cord: "Be careful with any abnormal finding in lower spine."

\section{Improve Communication ( $n=6 ; 4 \%)$}

Communicate better with other care providers. Be aware that communication issues with the patient can lead to error (eg, different language, culture, or ways of expressing concerns). Example: Missed spleen laceration after history of physical abuse withheld by patient: "Cultural factors can lead to withholding of crucial information."

\section{Arrange Better Follow-Up Care ( $n=13 ; 5 \%)$}

7.1. Arrange More Reliable, Specific Follow-Up $(n=11$; 4\%) Arrange better follow-up in specific circumstances; provide return parameters; take a more active role in arranging follow-up; physician should initiate follow-up, such as a phone call, not just leave it up to the patient. Example: Missed endometrial cancer: "Call patients on the phone and don't leave a follow up plan to the next visit. They can move!"

\subsection{Involve the Patient $(n=2 ; 1 \%)$}

Involve the patient in the uncertainty of diagnosis; involve the patient in specific circumstances. Example: Missed pneumonia: "Explain symptoms to family/patient that don't fit the diagnosis and if they develop, to be seen/call back immediately."

\section{Other Comments ( $n=12 ; 5 \%)$}

\subsection{Some Errors Are Fate $(n=2 ; 1 \%)$}

Recognize that some diagnostic errors will happen despite our best efforts. Example: Missed brain tumor: "[Bad stuff] happens."

\subsection{Comments Without Lessons ( $n=6 ; 2 \%)$}

Example: Missed endometrial cancer. "Patients can [crossed out 'will'] forgive you when you explain what happened."

\subsection{Questionnaire Item Requesting Lessons Left Blank} $(n=4 ; 2 \%)$ 